\title{
INFORMATION RESOURCES MANAGEMENT FOR POLICY FORMULATION, IMPLEMENTATION AND PROGRAMME DECISION-MAKING IN GOVERNMENT MINISTRIES IN TANZANIA
}

\author{
Fenella Mukangara \\ University of Dar Es Salaam, Dar Es Salaam, Tanzania
}

\begin{abstract}
This article discusses the findings of a study conducted on the state of information resources management (IRM) in government ministries in Tanzania. The purpose of the study was to investigate and establish the extent to which the information resources management in the ministries reflect and support the process of policy formulation, implementation and programme decision making. The study focused on the senior policy and decision makers in the government ministries as well as the heads of information resource domains of the ministries. The article argues that IRM is a management concept with a unique perspective that has a potential, when implemented, to improve government ministries' efficiency and effectiveness. Through IRM better organization of information and information technology to meet the information needs of ministries policy and decision makers would be achieved. The study established the state of IRM in government ministries in Tanzania to be poor.
\end{abstract}

\section{Introduction}

Studies (Tanzania and UNDP, 1991; Tanzania. Nsekela Commission, 1987; Tanzania. Kisumo Commission, 1984) on the Civil Service in Tanzania have revealed numerous performance-related problems. This has been characterized by poor delivery of public services in all areas of the civil service, namely, governance, resources, personnel and management. The Civil Service is the executive arm of the Tanzanian government responsible for implementation of government policies. The Presidential Commission of inquiry on the state of corruption in Tanzania reported the presence of corruption in practically each and every area of government function (Tanzania Presidential Commission, 1996). The commission's report observed that corruption was caused, among other things, by problems in implementing laws and regulations; lackadaisical administration and inadequate accountability; lengthy and cumbersome procedures for obtaining public services; managerial weaknesses of state organs, and lack of transparency in the economy. 
Additionally, lack of reliable information due to poor record keeping was one of the main barriers the commissioners reported in their findings. The poor record keeping pertained to most of the areas of government functions (Tanzania Presidential Commission, 1996:5).

This study investigated the extent to which information resources management for policy formulation, implementation, and programme decision making exist in government ministries in Tanzania. The premise of the study was that through effective IRM, which is a stage in information management process, policy and decision makers can plan opportunities to secure accurate and timely information that will enable them to make informed decisions.

The study highlights the need for the policy and decision makers in Tanzania to understand, that information like other important resources is a fundamental management responsibility. Most of the activities of a government organization are intrinsically information processing in nature; therefore, a typical government organization such as a government ministry in Tanzania must see information and information handling activities as the core and essence of its operations if it is to do away with poor delivery of public services. This will facilitate the government decision making process by making available the right information at the right time. It is also assumed that successful implementation of IRM in government ministries in Tanzania would depend on how decision makers perceived the importance of information in their decision making process with regard to policy formulation, implementation and programmes implementation.

\section{Literature Review}

In the past two decades many have come to conclude that information is a critical resource that needs to be professionally managed in organizations. Executives, administrators, managers, and professionals in all fields and levels need information for making informed decisions in their work (Ouma-Onyango, 1997; Huber et al., 1990; Langemo, 1988; Miller, 1987; Taylor, 1986; Vickers, 1984). The absence of accurate, relevant, and timely information often leads to inappropriate decision making in organizations (Langemo, 1988). It is therefore common in recent times to emphasize the availability and accessibility of quality information as the basis for making informed decisions in organizations. In other words when accurate, relevant 
and timely information is not available at the executive level in the organizations, it will not be seriously considered at policy making either (Langemo, 1988; Taylor, 1986; Vickers, 1984).

Information resources management (IRM) is the process of managing information resources such as information itself, information handling technologies (computer hardware and software, and telecommunications), personnel (with information related skills), and the financial resources to accomplish the organization's mission. IRM seeks to establish the necessary means for an organization to create or acquire, process, and store data, information and knowledge of quality, timeliness, and accuracy to support organizational goals (Cronin, 1991; Langemo, 1988; Marchand and Kresslein, 1988; Trauth, 1989). IRM implementation in organizations is a means of getting the right information at the right time in the right form to the right person (Beath and Straub, 1991; Langemo, 1988; Trauth, 1989).

Based on the general observations from existing literature one may argue that lack of effectiveness on the part of the government in meeting its service objectives and mandated responsibilities is a consequence of the lack of information resources management. OumaOnyango (1997) in their investigation of the state of information resources management for policy formulation, implementation and programme decision making in government ministries in Tanzania, sought to identify efforts, if any, that the government has made over the years to institute IRM in government functions. In Tanzania, several economic programmes need to be in place, and accurate, timely information is needed for both government and private sector initiated programmes to succeed. The study observes that not only is information an essential requirement for effective and efficient management in organizations, it is also a basis for medium and long term planning.

Studies (Ouma-Onyango, 1997; Caudle, 1996; Akhtar et al., 1994; Akhtar, 1994) argue that for information management in government to succeed there is a need for the creation of a coordination unit for information management in the government of Tanzania. This unit is to offer a means of addressing the information flow within the government institutions and between government and society at large. This coordination mechanism should address issues concerning the harmonization of information activities within and between 
government ministries. Furthermore, this unit should fit into a well articulated national policy related to information. Policies are needed to ensure the consistency of decisions taken in matters of importance, and that information is one of those important matters especially when we speak of information as a potentially profitable resource (Ouma-Onyango 1997). An information policy can be used as a tool for developing an organizational information strategy. It can also be used to relate everything that is done with information to each of the government ministries overall objectives, in order to promote interactions, communications and mutual support between all divisions of the ministries and between the ministries and the public. It is in this respect that legislatively mandated information management was regarded as essential for information resources management to occur in ministries. In other words, effective IRM in ministries would only be feasible if an information policy was instituted in order to provide the legal and institutional frameworks within which formal information exchange can take place.

Literature review (Mukangara, 2000; Rugumyamheto, 1991) shows that for every policy which is formulated some kind of information searching and use need to take place. Policies are therefore analyzed or researched in their formulative stage or even at the level of implementation in order to establish how they can effectively be addressed and enable the government to accomplish its roles. Adequate information upon which policies and decisions are based need to be readily available. Information resources management seeks to establish the necessary means for an organization to create or acquire, process and store information and data of adequate quality, timeliness and accuracy to support organizational goals. One of the major prerequisites for IRM to occur is the need for effective organizational information policies. Similarly an existence of a well articulated national information policy framework can, among other things, ensure the presence of effective organizational information policies and consequently IRM in government ministries in Tanzania (Mukangara, 2000).

\section{Methodology}

The study was exploratory in nature. The primary research design of the study comprised of a survey of policy and senior decision makers in government ministries, and the information resources management personnel of the ministries. 
The units of analysis were firstly, individual office bearers as policy and decision makers of their ministries and the way they obtained information for policy formulation implementation and programme decision making. Secondly, the information domain personnel in the ministries formed another unit of analysis. All were by virtue of their positions and responsibilities expected to influence the state of information resources in their ministries. The study was conducted between August 1998 and March 1999. Twenty three ministries out of the then twenty four ministries were surveyed. A total of 80 out of 94 policy and decision makers and 44 out of 64 heads of the information resource domains responded. In this study the information resources domains of the government ministries were those formal information holdings available to the ministries that contribute towards making information available and accessible to executive policy and decision makers.

The choice of the survey methodology was dictated by the nature of the problem being studied and the data to be gathered. The perceptions and views of decision makers in regard to the availability of the information they use for policy and decision making was deemed important. Equally important was the condition of the information domains of their ministry. Sproull (1995:30) recommends survey technique as an appropriate method to be employed "especially when attitudes, ideas, comments and public opinion on a problem or issue were being studied." Surveys have been used in other similar studies, particularly those seeking to establish information utilization by policy and decision makers as well as those seeking to establish the extent of information management and information resources management in the public sector and other organizations (Bergeron, 1996; Caudle, 1996; Caudle, et al 1989; Lewis and Martin, 1989; Powers, et al 1987).

Two sets of self administered questionnaires were designed to serve as the main data gathering instruments. Other methods used included informal meetings with some senior officials in the ministries and observations in the various ministries information resource domains. In addition, a check list aimed at collecting primary data on the state of the information handling facilities of the surveyed ministries head offices was distributed to 22 ministries. One ministry declined to participate in the in-depth narration of its capacity as far as information handling facilities were concerned. 
The choice of questionnaires as the major means for data collection was based on the type of the study and the nature of the respondents. The literature (Leedy, 1997; Babbie 1992) observes that questionnaires normally give respondents a feeling of anonymity which in turn encourages openness to questions. This is by virtue of the instrument's ability to provide a medium that enables one to observe data beyond the physical reach of the observer. This data collection technique suited this study which aimed at establishing the respondents' perceptions while at the same time ensuring their anonymity.

\section{Findings}

National information policy and its effect on IRM in ministries in Tanzania

This study found that there is no national information policy framework or a coordinating unit for all information management related activities in government ministries in Tanzania. About $79 \%$ of the policy and decision makers, as well as $90 \%$ of the heads of the information domains recommended the institutionalization of a national information policy, among other things, as a way to solve some of the information related problems they faced. The study identified a number of fragmented policies, regulations, executive decisions and organizations related to information field in Tanzania; for example, Tanzania Communications Commission, Tanzania Broadcasting Commission, Science and Technology Commission, Tanzania Industrial Research and Development Organization, Tanzania Industrial Studies and Consulting Organizations, National Scientific Research Council, Tanzania Information Services, National Archives, Library Services Board; all of which are situated under different government ministries. The study findings established that despite their existence over a decade, these bodies did not ensure the availability and accessibility of quality, timely and accurate information to policy and decision makers in the government ministries. Based on the findings one can say that these information related bodies/entities operated in oblivion of the existence of the other, making it possible for the study to establish that their information related policies are uncoordinated and a mechanism for their coordination is missing (Mukangara, 2000).

The study contends that coordination can be attained in the form of a national information policy framework with one functioning 
coordination unit legislatively mandated with powers, resources and the expertise to identify gaps that exist in the categories of a national information policy (Rowland, 1996a / b:20). The current situation in Tanzania is that there is no information and communication technology policy in place, neither is there an overall policy for government information resources management. Information and communication technology is perceived as an enabling technology to facilitate the delivery of information once the users, needs and appropriate committees have been clearly defined.

Modern economic, social, and political activities depend on a constant flow of information, while telecommunication is one of the basic technologies needed for any new information and communication technology to be viable. To date Tanzania lacks adequate basic telecommunication services which are essential to economic growth, administrative efficiency, security and the welfare of the citizens. The absence of reliable communication links particularly in terms of telecommunication links to the whole country acts as a major barrier to the national social, economic and political mobilization of the meagre resources available, which are vital to good governance, law and order (Tanzania. Telecommunications, 1997).

With such a situation prevailing and the existing tendency of the current information related bodies operating in isolation of the other; it is not surprising that the information resources management per se in government ministries is poor (Mukangara, 2000). Thus focus on the management of information and the purposes for which it could be applied, and the support that technologies could provide to these policy and decision making processes should be part and parcel of information resources management in ministries. A clearly thought out framework for information management can usefully guide an integrated policy making process, so that decisions can be coordinated and made on the basis of informed choice. For this to happen, information policy or coordinating body of some kind, with regulatory authority would have to be in place and would need to be fully functional.

\section{Awareness on the role and importance of information management}

The study found that $97.50 \%$ of the policy and decision makers are aware of the role and importance of information in the decision making. This is further established in their frequent use of the 
information resource domains of their ministries. Furthermore, the information sharing within and between ministries was reported by $52.63 \%$. The study also found that policy and decision makers consider policy and planning units as their main information resource. The need to obtain information from other ministries was also reported by $96.25 \%$ of the policy and decision makers as "very important" and "important".

Although the study found that policy and decision makers are aware of the importance of information, their general perception pertaining to the importance of properly organized information management is quite evident. For example, the study found that although policy and planning units were reported to be the information resource domain for policy and decision makers in each ministry, the practice was for the senior officers dashing all over (bush walking as some senior officials put it) within and between ministries in order to get the information they needed. The ministries mostly used are the planning commission, civil services, Prime Minister's Office and the treasury. Included also are the academic institutions and non governmental organizations.

The study also found that $33.75 \%$ of the policy and decision makers reported Permanent Secretaries and $31.25 \%$ reported all directorates within their ministries as sources of information for policy and decision making in their ministries. Policy and planning units of the ministries were reported by $18.75 \%$ as one of the sources of information for policy and decision making in ministries. Further more, $66 \%$ of the policy and decision makers reported not relying on the policy and planning unit for information. The implications of this non-reliance is viewed by the researcher as simply a manifestation of the inability of the unit to meet the information needs of its users; the policy and decision makers.

The inadequacy of the policy units to meet the information needs of the policy and decision makers is not surprising, as the units operations are not based on the information needs of the policy and decision makers in the first place. In addition, $62.50 \%$ of the policy and decision makers reported not getting the information they needed when they needed it. This is mainly due to the fact that information identification, collection, organization, retrieval, facilitation of its use, 
and tools necessary for these processes are not in place and where present they are not coordinated (Mukangara, 2000).

Mechanisms available for information resources management in ministries

The study found out that mechanisms for information resources management are lacking. These are both in terms of policy, procedures and a formal senior management positions in the ministries for a skilled information handling personnel responsible for availability of information for policy and decision making. For example, $43.75 \%$ of the policy and decision makers reported lack of availability and $10 \%$ did not know if a policy or set of procedures existed. Furthermore, the study shows that there is no effective formalized means available in ministries for providing information to the policy and decision makers in ministries. For examples, no formal structure in the form of an advisory group or steering committee for managing information in ministries was reported to exist except on an ad hoc basis when the need arose. Thus even in their quest for information that quite often took policy and decision makers to other ministries, they depended on their colleagues stationed in the other ministries. Furthermore, qualified and skilled support staff in the ministries who were up to date with information resources management developments and techniques were lacking (Mukangara, 2000:184-185).

There was a general perception that the director and other senior officers in the policy and planning department were responsible for the policy and decision makers' information needs and therefore responsible for the information availability and its management. In practise the study found that the policy and decision makers had to go out of their way to get the information they needed and more often they do not get it at the time they needed it. This situation establishes further that the art of information seeking and information management per se require extra skills on the part of those responsible for information handling and provision at policy and decision making level (Mukangara, 2000).

\section{State of information resources management in the ministries}

The study found out that mechanisms for information resources management are lacking. That is, there is no clearly established process for managing information resources to accomplish ministries' missions. The study established that $100 \%$ of ministries are still at the 
rudimentary records management stage; that is, supervisory, clerically handled services mostly viewed as a support function. This situation results in available information resources not attracting much attention from the senior management of the ministries. The state of IRM in ministries was found to be rudimentary because even the records management as we know it, was not properly carried out. Effective records management per se cannot be said to be taking place in the ministries, where poor state of the National Archives was established. This poor state of archives had a spill over effect, leading to high congestion in ministry registries, which are mostly managed by unqualified staff, and lack the necessary facilities to enable smooth functioning of the sections.

Policy and planning units or divisions of ministries are considered by $66 \%$ of policy and decision makers as well as the majority of the information resource domains personnel of the ministries to be responsible for the information for the policy and decision makers in ministries. The study found the functions of these policy and planning sections are restricted in terms of provision of information for policy formulation, implementation and programme decision making. The limitation is by virtue of the policy and planning divisions lacking clearly articulated policy and procedures that define their role as an information resource for the policy and decision makers. In meeting this obligation the responsible sections in ministries' policy and planning divisions will have to define clearly how information can be more efficiently collected, stored, processed, and disseminated for the purpose of meeting policy and decision makers' information needs. This would entail the information resource domains of the ministries, particularly the relevant sections in policy and planning divisions of the ministries, defining why particular information is collected in the first place, and what practical value it has or will have in helping achieve ministry programmes. This means information management has to be established in the ministries. In order for information management to take place in the ministries, information management has to be something that the policy and decision makers (top management) of the ministries care about and participate in. The current situation is that these policy and planning divisions lacked information management vision for their ministries which could have been in place if information resources management was adopted. 
The study also found that the information resources management handling capacity of the ministries is inadequate. This is both in terms of information technology that is, computers, telecommunications and office systems, as well as information handling skilled personnel at all levels. The information resource domains, for example, libraries where available, and registries, are ill staffed and inadequately managed.

\section{Barriers to information resources management}

The study found that barriers to information resources management include those associated with lack of knowledge among policy and decision makers as to what constitutes information management. Furthermore, there were barriers to information resources management, the addressing of which were within the capabilities of the ministry if policy and decision makers articulated the need for information management and identified it as an issue to be addressed. Examples of such barriers were; lack of resources in terms of finance, personnel (a general lack of professionally trained personnel at all levels to manage information, absence of senior personnel professionally trained in information management fields and skills); equipment to manage information, and lack of established procedures for the collection, management and use of information within and between ministries. The study also found barriers which are outside the control of the ministries' top management, for example, lack of government wide information resources management policy or a blue print that gives substance to the need for information management in government. This limitation also implies information was not viewed as a resource in ministries.

\section{Conclusions}

This study established the general lack of information resources management for policy formulation, implementation and programme decision making in the ministries. Some possible explanation for this state is the low level of information resources management that was found to exist in the ministries. The lack of awareness among policy and decision makers on the role and importance of information resources management for policy formulation and decision making is another explanation. This lack of awareness is manifested in the existence of various barriers to the process of information resources management in ministries. One of the barriers is the general perception among policy and decision makers on the perceived ability 
of managing information by any senior staff, regardless of their training.

The study has shown that the senior staff, even in the designated areas for provision of information to the policy and decision makers that is in the policy and planning units of the ministries, do not manage information per se. In most cases they are users who have to consult the information resource domains in and out of their ministries, other organizations and colleagues. The information that these senior staff get and decide to use will depend on how far they are prepared to put their information searching skills to task. In most cases they have the final say on what information to use. In addition, the study also found lack of clarity about whether or not mechanisms to measure the impact of information are used at all. What comes across in the study is at most a remote possibility that the impact of the information used by policy and decision makers is known. This situation coupled with lack of clearly articulated mechanisms for accountability of information used for policy and decision making, makes the need for information management in ministries more pressing.

The study's findings also imply that the policy and decision makers' operations are affected by the lack of clearly stipulated policies and procedures for information sharing and access within and between ministries. Researchers produce a variety of statistics and indicators that describe the social and economic climate of countries and this information is used by government and private sector decision makers in their planning and policy making activities. In that process of policy and decision making, planners and economists, who make the core of the policy and decision makers in this study, need rapid and cost effective access to information and information resources. Their decisions and the general public are affected by the availability, accessibility and credibility of data and information that they use.

What also emerges from the study is that ministries share information on an ad hoc basis in response to immediate requests; they may even share the incorrect information or information which is not current. In other words information sharing within and between ministries is a sort of hit and miss activity. Therefore, based on the study's findings it is correct to conclude that the state of information resources management in the government is poor. 
The minimum level that exist, also does not have the capacity to acquire, store or effectively access all the necessary information available for the purpose of policy formulation, implementation and programme decision making. That is, they can only consult a limited amount of the information available based on the state of information resource domains established in the study.

For instance, new kinds of technology (computerisation and its software of various capabilities) are used to produce, store and access information. But the study shows most ministries' information resource domains cannot afford to own, much less effectively use, the different equipment they need to handle the different media through which information is made available. This is an indication of lack of information resources management in government ministries. Therefore, a way must be found to make existing information more accessible and to coordinate the production and dissemination of new information.

Based on the research findings, the need to manage information upon which policy and decision makers' deliberations are based, requires attention; thus the need to institute a new and improved outlook and approaches to information and information management at various levels in ministries and government as a whole. For this to happen, a significant amount of education and training in information science disciplines will be needed to provide the human infrastructure and knowledge base needed for effective information technology use.

\section{Recommendations}

One of the objectives of this study was to recommend possible solutions based on the study's findings on information resources management in the ministries and accessibility of information to decision makers. Thus one of the main recommendations emanating from the findings of this study is the institutionalising of an information resources management policy for the government. A well articulated information resources management policy for the government could be encompassed under the broad framework of a national information policy which is responsive to public and private sector information needs and priorities. A national information policy framework operationalized under a coordination unit with a legislatively or executively mandated authority could define and 
make clear the kind of leadership needed for the information resources management policy in government to occur.

It is the contention of this study that this need for leadership is probably the first and foremost challenge, as it reveals that a leadership vacuum exists in the area of senior information management in government ministries; and there is no single body or institution that is mandated to take leadership.

\section{References}

Akhtar, S. and M. Melesse. (1994). "Africa, information and development: IDRC's experience." Journal of information science, 18, 283-292.

Akhtar, S., W. Melody and D. Naidoo. (1994). National information project: South Africa report for an IDRC mission, 14-25 November. Johannesburg: IDRC.

Babbie, E. (1992). The Practice of Social Research. 6th ed. Belmont: Wadsworth.

Beath, G.M. and D.W. Straub. (1991). "Department level information resources management: a theoretical argument for a decentralized approach." Journal of the American Society for Information Science, 42 (2),124-27.

Bergeron, P. (1996). "Information resources management." In: Williams, M. E. (ed.) Annual Review of Information Science and Technology. Medford: Information Today. 31: 263-300.

Caudle, S. L. (1996). "Strategic information resources management: fundamental practices." Government Information Quarterly, 13(1), 83-97.

Caudle, S. L., D. A. Marchand and S. I. Bretschneider. (1989). Managing information resources: new directions in state government. Sycracuse: Sycracuse University.

Cronin, B. and E. Davenport. (1991). Elements of information management. Metuchen: Scarecrow Press. 
Huber, G.; C. C. Miller and W. H. Glick. (1990). "Developing more encompassing theories about organizations: the centralization effectiveness relationship as an example." Organization Science $1(1), 11-33$.

Langemo, M. (1988). "An introduction to information resources management." ARMA Records Management Quarterly, 22(4), 2028.

Leedy, P. (1997). Practical research planning and design 5th ed. New York: Macmillan.

Lewis, D. A and W. J. Martin (1989). "Information management: state of the art in the United Kingdom." Aslib Proceedings, 41(7/8), 225-25.

Marchand, D. A. and J. C. Kresslein. (1988). "Information resources management and the public administrator." In: J. Rabin. and E. M. Jackowski. (eds). Handbook of information resource management. New York, NY: Marcel Dekker pp.395- 455.

Miller, B. B. (1987). "Managing information as a resource." In: J. Rabin, and E.M. Jackowski (eds). Handbook of information resource management. New York, NY: Marcel Dekker pp.3-33.

Ouma-Onyango, R. A. (1997). Information resources and technology transfer management in developing countries. London: Routledge.

Powers, G. and N. J. Williams. (1987). "An information strategy for state government: the case of South Carolina." Information Management Review, 3(2), 31-46.

Rowlands, I. (1996a). Understanding information policy: proceedings of a workshop held at Cumberland Lodge Windsor Great Park, 22-24 July, London: Bowker-Saur.

Rowlands, I. (1996b). "Understanding information policy: concepts, frameworks and research tools." Journal of Information Science, 22(1), 13-25. 
Rugumyamheto, J. A. (1991). Role of policy analysis and review units in the civil service. In: URT and UNDP. Strengthening management in the public sector: civil service reform programme project: Launch Workshop report, URT 90/031 November.

Sproull, N. L. (1995). Handbook of research methods: guide for practitioner and students in the social sciences. $2^{\text {nd }}$ ed. Metuchen, New Jersey: Scarecrow.

Tanzania. (1987). The Nsekela Commission, report of the salary review commission, Vol. I and II. Dar es Salaam, Government Printers.

Tanzania. Ministry of Communications and Transport. (1997). National telecommunications policy. Dar es Salaam: Ministry of Communications and Transport.

Tanzania Planning Commission, (1984). Kisumo Commission Report. Dar es Salaam.

Tanzania. Presidents office. (1996). Presidential commission of inquiry against corruption in the country Vol. 1, II, and executive summary. Dar es Salaam: Government printers.

Tanzania. and UNDP. (1991). Strengthening management in the public sector: civil service reform programme project: Launch Workshop report, URT 90/031 November. Dar es Salaam: Civil Service Programme.

Taylor, R. S. (1986). Value added processes in information systems. Norwood: Ablex.

Trauth, E. M. (1989). The evolution of information resources management. Information management. 16(5):257-268.

Vickers, P. (1984). "Promoting the concept of information management within organizations." Journal of information science, 9,123-127. 